\title{
An Observational Study of Retail Pharmacy Naloxone Prescriptions: Differences Across Provider Specialties and Patient Populations
}

\author{
Rosanna Smart, $\mathrm{PhD}^{7}$, Caroline K. Geiger, $B A^{2}$, Christopher M. Jones, PharmD, $M P H^{3}$, \\ and Bradley D. Stein, $M D, P h D^{1,4}$
}

'RAND Corporation, Santa Monica, CA, USA; ${ }^{2}$ Harvard University, Cambridge, MA, USA; ${ }^{3}$ Centers for Disease Control and Prevention, Atlanta, GA, USA; ${ }^{4}$ University of Pittsburgh School of Medicine, Pittsburgh, PA, USA.

BACKGROUND: Despite exponential growth in pharmacy-dispensed naloxone, little information is available regarding variation in naloxone prescribing pattern across specialty groups, regions, and patient populations. OBJECTIVE: Explore variation in pharmacy-dispensed naloxone by prescriber specialty and patient characteristics.

DESIGN: Cross-sectional analysis of the 2016 national retail pharmacy naloxone prescription claims from the IQVIA Real Longitudinal Prescriptions database.

PARTICIPANTS: Naloxone prescribers and individuals filling naloxone prescriptions.

MAIN MEASURES: Descriptive statistics assess differences across prescriber specialty groups in number of naloxone prescribers, patient and prescription characteristics, and geographic variation in naloxone dispensation and naloxone market share across prescriber specialty groups or formulation.

KEY RESULTS: In 2016, 100,958 naloxone prescriptions written by 14,026 prescribers were filled by 88,735 patients. Primary care physicians accounted for the largest share of naloxone prescribers (45.9\%); pain and anesthesia physicians and non-physicians prescribed to significantly greater numbers of patients (means of 10 and 8, respectively). While responsible for a relatively small share of naloxone dispensed (6.1\%), psychiatrists and addiction specialists disproportionately served younger individuals, accounting for $49.5 \%$ of all prescriptions for individuals aged 35 and younger. Naloxone fill rates differed greatly across geographic regions, with the highest per capita rates in New England and the most concentrated prescribing in the West South Central and South Atlantic regions, where naloxone prescribers had the highest average numbers of patients (9.7 and 7.9, respectively). The South Atlantic and West South Central also had naloxone markets dominated by the Evzio ${ }^{\circledR}$ auto-injector, responsible for 50.3\% and $43.8 \%$ of all naloxone dispensed in the regions; in contrast, New England's naloxone market was predominantly comprised of generic formulations (48.8\%) and Narcan ${ }^{\circledR}$ nasal spray (45.4\%).

Prior presentations None.

Electronic supplementary material The online version of this article (https://doi.org/10.1007/s11606-019-05448-y) contains supplementary material, which is available to authorized users.

Received August 16, 2019

Accepted September 26, 2019

Published online October 21, 2019
CONCLUSIONS: Our findings reflect a need to better understand barriers to uptake of naloxone prescribing behavior among physicians and other prescribers to ensure individuals have adequate opportunity to receive naloxone from their treating clinicians.

KEY WORDS: naloxone; prescribing patterns; pharmacy.

$\mathrm{J}$ Gen Intern Med 35(6): 1768-75

DOI: $10.1007 / \mathrm{s} 11606-019-05448-\mathrm{y}$

(c) Society of General Internal Medicine 2019

\section{INTRODUCTION}

In 2017, approximately one in sixty deaths in the US was opioid-related, representing over 1.7 million years of life lost. ${ }^{1,2}$ Continued escalation of overdose fatalities due to the rapid proliferation of highly potent synthetic opioids such as fentanyl have furthered calls to expand the availability of naloxone, a short-acting opioid antagonist effective in counteracting opioid overdose-related central nervous system and respiratory depression. ${ }^{3,4}$ Paramedics and medical professionals within emergency departments have long used naloxone for opioid overdose reversal, but the opioid crisis has spurred local, state, and federal actions to extend naloxone availability to laypersons. ${ }^{5}$

In recent years, the volume of naloxone prescriptions dispensed through retail pharmacies has dramatically increased, with a more than tenfold increase between 2013 and $2015,{ }^{6}$ a trend that appears to have persisted through $2018 .^{7,8}$ Multiple efforts have likely contributed to this growth, including state and federal efforts to expand pharmacy distribution of naloxone, such as standing order policies and federal guidelines supporting naloxone co-prescribing to patients receiving longterm or high-dose opioid therapy. ${ }^{9-11}$ Such efforts continue, as exemplified by efforts to increase the likelihood of naloxone becoming available over-the-counter. ${ }^{12}$ But with state standing order and third-party prescription laws in almost all states obviating the need to obtain a prescription, it is unclear to what extent this will meaningfully change the amount of pharmacy-distributed naloxone, and over-the-counter status might have the unintended consequence of increasing the cost 
of naloxone for individuals for whom prescription insurance coverage will no longer apply.

To date, however, there is a paucity of information about the number and nature of clinicians prescribing naloxone. To address this gap, we used the 2016 transaction-level retail pharmacy claims to explore patterns of naloxone prescriptions being dispensed, including variation in the characteristics and geographic distribution of prescribers. Such information can provide insights regarding to what extent naloxone prescribing is widespread or concentrated among a relatively small number of prescribers and the degree to which naloxone is prescribed by different clinician specialties, such as pain specialists, who are common prescribers of opioid analgesics. Furthermore, understanding geographic variation in naloxone prescribing practices can illuminate whether certain regions continue to face barriers in access to naloxone. Taken together, this information can help better target opioid overdose prevention and response efforts.

\section{METHODS}

\section{Data}

We examined naloxone prescriptions dispensed through retail pharmacies in 2016 using de-identified pharmacy claims from the IQVIA Real World Data - Longitudinal Prescriptions, which covers an estimated $88 \%$ of all prescriptions filled at retail pharmacies in all 50 US states and the District of Columbia for all payers and contains information on the prescription, patient demographics, prescribing provider specialty, and pharmacy location of the filled prescription. The corresponding author's Institutional Review Board approved the study.

\section{Measures}

Naloxone prescriptions were identified using National Drug Codes and categorized by generic formulation, Narcan $®$ nasal spray, and Evzio ${ }^{\circledR}$ auto-injector. Prescribers were categorized based on their specialty into seven specialty groups: primary care (including internal medicine and adolescent/pediatrics); non-physicians (primarily nurse practitioners and physician's assistants); pain and anesthesia physicians; psychiatry and addiction specialists; emergency medicine; surgeons; and other specialties (see eTable 1 in the ESM). Patients were categorized by gender and age group (under 18 years, 18-35, 36$45,46-65$, and over 65 years). Using information on the location of the pharmacy filling the naloxone prescription, we categorized naloxone prescription fill locations into the nine US census divisions: Pacific, West North Central, East North Central, West South Central, East South Central, South Atlantic, Middle Atlantic, and New England.

\section{Analysis}

First, we calculated the number of patients filling naloxone prescriptions and the number of filled naloxone prescriptions for each prescriber. Second, we aggregated by prescriber specialty group the total number of naloxone prescriptions dispensed, overall and by formulation, as well as the number of associated patients dispensed naloxone. Third, by census division, we calculated per capita rates of dispensed naloxone and naloxone prescribers, naloxone prescriptions per opioid overdose deaths, the percentage of dispensed naloxone prescribed by each specialty group, and the percentage of dispensed naloxone by formulation. Descriptive statistics (means, medians, and percentiles) were used to assess variation in number of patients per prescriber across specialty groups and across US census divisions. Finally, we explored gender and age distribution of patients served by different specialty groups. For comparisons of prescription fills or prescribers across census division, per capita rates were calculated using the 2016 population estimates from the Area Health Resource Files. For comparisons of prescription fills accounting for differential opioid overdose mortality across census divisions, counts of opioid overdose deaths were obtained using 1year lagged (2015) data from the Centers for Disease Control and Prevention ${ }^{13}$ following the definition used in prior work. ${ }^{14}$

Statistical significance was assessed using ANOVAs for continuous outcomes and chi-square analyses for categorical outcomes. Post-hoc Bonferroni corrections were used to adjust for multiple comparisons.

\section{RESULTS}

In 2016, a total of 100,958 naloxone prescriptions written by 14,026 prescribers were filled by 88,735 patients through retail pharmacies. Naloxone prescriptions were split between branded Narcan ${ }^{\circledR}$ nasal spray $(n=37,022 ; 36.7 \%)$, branded Evzio ${ }^{\circledR}$ auto-injector $(n=34,142 ; 33.8 \%)$, and generic formulations ( $n$ $=29,794 ; 29.5 \%)$. Approximately half of patients receiving naloxone were female $(53 \%)$, and $48 \%$ were over age 50 . Primary care physicians accounted for the largest share of naloxone prescribers $(n=6437 ; 45.9 \%)$, followed by nonphysicians $(n=3504 ; 25.0 \%)$, and pain or anesthesia physicians $(n=2021 ; 14.4 \%)$. Psychiatrists and addiction specialists $(n=872 ; 6.2 \%)$, emergency medicine physicians ( $n=857$; $6.1 \%)$, and surgeons $(n=271 ; 1.9 \%)$ each represented less than $10 \%$ of naloxone prescribers (Table 1 ).

Although primary care physicians accounted for the largest percentage of prescribers, the mean number of patients prescribed naloxone by each primary care physician $($ mean $=4.8$; $\mathrm{SD}=40.5)$ was less $(p<0.001)$ than the mean number of patients prescribed naloxone by pain and anesthesia physicians $($ mean $=10.0 ; \mathrm{SD}=28.3)$ and non-physicians (mean = $8.2 ; \mathrm{SD}=30.2)$ (Table 1). Therefore, while non-physicians and pain and anesthesia physicians accounted for $31.2 \%$ of naloxone prescribers, in aggregate, they accounted for $54.8 \%$ of patients receiving naloxone prescriptions. 


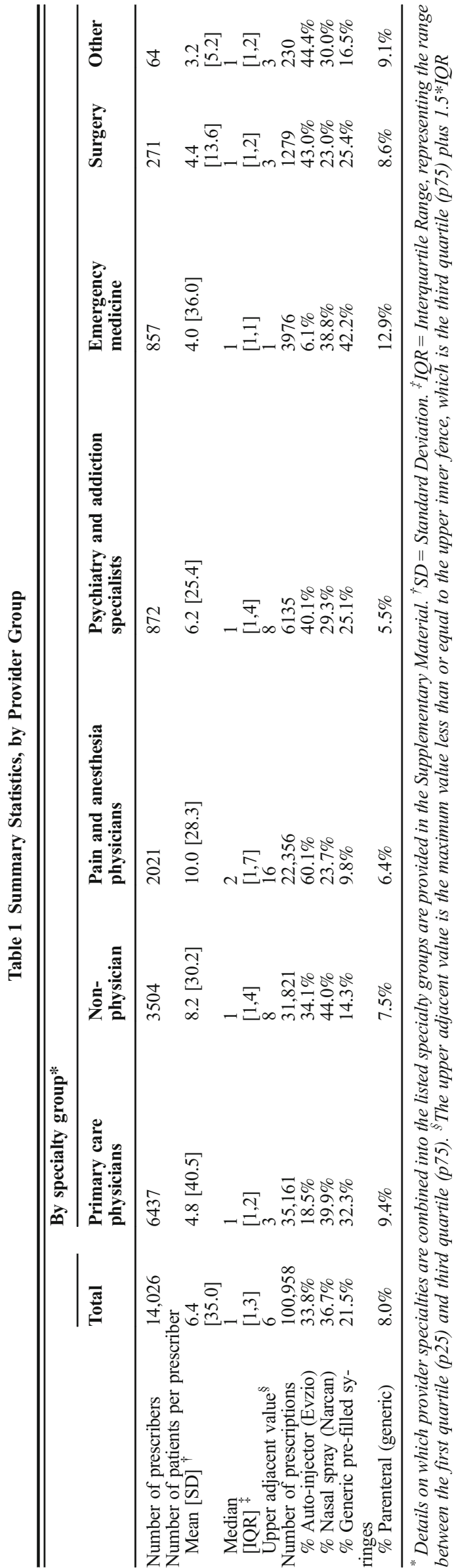

There was substantial variation in both per capita dispensing of naloxone prescriptions and the percentage of naloxone prescriptions written by different specialty groups across census divisions. As Figure 1. highlights, New England exhibited the highest per capita rates of dispensed naloxone prescriptions ( 98.5 per 100,000 persons), more than double that of the census divisions with the next highest rates, the South Atlantic (45.6), Mountain (42.3), and East South Central (38.3) census divisions. The lowest per capita rates were observed in the West North Central (10.4), followed by the East North Central (20.6), Mid Atlantic (20.6), and West South Central (20.8) census divisions. Maps by specialty group and formulation are available in the ESM.

Per capita rates of naloxone prescribing mirrored the pattern of per capita prescribers, with the highest rate of prescribers per capita in New England (15.9 per 100,000 persons), more than threefold the rate of naloxone prescribers in all but one other census division (Mountain) (Table 2). The Mountain (6.5), South Atlantic (5.1) and East South Central (4.5) census divisions had the next highest rates of naloxone prescribers, consistent with their comparable rates of naloxone prescriptions dispensed. New England and the South Atlantic also had more naloxone prescriptions per opioid-related overdose deaths (4.5 and 4.0, respectively) than other divisions. However, in the South, naloxone prescribing tended to be more concentrated among fewer prescribers. Naloxone prescribers in the West South Central and South Atlantic divisions wrote prescriptions for the highest average numbers of patients $(9.2$ and 7.9 patients per prescriber, respectively), means significantly higher than those of prescribers in the Pacific (mean = 4.6 patients per prescriber; $p=0.033$ ) and Mid-Atlantic (mean $=4.3$ patients per prescriber; $p=0.022$ ).

The geographic variation in per capita dispensing of naloxone prescriptions was accompanied by significant variation in prescribing rates by different specialty groups (Table 2 ). In both New England and the Mid-Atlantic, primary care physicians wrote $59.9 \%$ and $53.8 \%$ of dispensed naloxone prescriptions, respectively, while in the West South Central, $52.0 \%$ of dispensed naloxone prescriptions were written by pain and anesthesia physicians. Other notable patterns include the large percentage of dispensed naloxone prescriptions written by non-physicians in the Mountain West (40.4\%), South Atlantic (41.1\%), and East South Central (43.3\%) divisions, whereas no other census division had more than $30 \%$ of dispensed naloxone prescriptions written by non-physicians. Furthermore, in the East North Central division, $13.5 \%$ of all naloxone prescriptions were written by emergency medicine physicians, a specialty responsible for no more than $5 \%$ of dispensed naloxone prescriptions in other census divisions.

The type of naloxone dispensed also varied across census divisions. The proportion of Evzio $®$ auto-injector naloxone prescriptions was highest in the South Atlantic (50.3\%) and West North Central (45.6\%) and lowest in New England $(5.8 \%)$. In contrast, the proportion of Narcan ${ }^{\circledR}$ nasal spray naloxone prescriptions was highest in the East North Central 


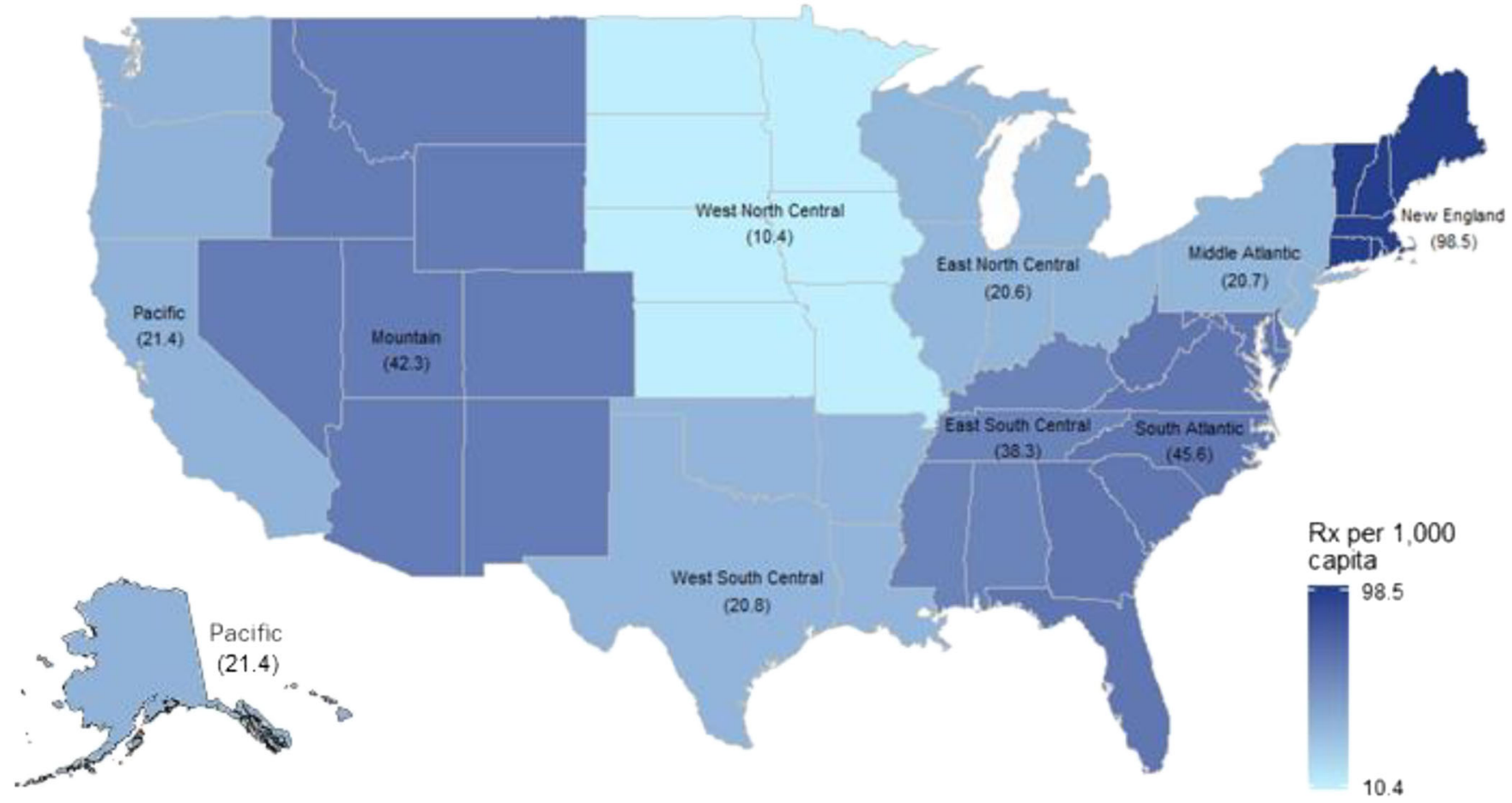

Figure 1 Geographic Variation in Per Capita Rates of Naloxone Prescriptions Dispensed through Retail Pharmacies, 2016. Darker shading indicates higher rates of naloxone prescribing. New England: Maine, New Hampshire, Vermont, Massachusetts, Connecticut, Rhode Island. Mid-Atlantic: New York, Pennsylvania, New Jersey. South Atlantic: West Virginia, Maryland, Delaware, Washington D.C., Virginia, North Carolina, South Carolina, Georgia, Florida. East South Central: Kentucky, Tennessee, Alabama, Mississippi. West South Central: Texas, Louisiana, Oklahoma, Arkansas. East North Central: Michigan, Wisconsin, Illinois, Indiana, Ohio. West North Central: North Dakota, South Dakota, Nebraska, Kansas, Missouri, Minnesota, Iowa. Mountain: Idaho, Montana, Wyoming, Colorado, Utah, Nevada, Arizona, New Mexico. Pacific: Alaska, Washington, Oregon, California, Hawaii.

(50.8\%) and New England (45.4\%). The proportion of generic naloxone comprising total dispensed prescriptions ranged from a high of $48.8 \%$ in New England to a low of $13.2 \%$ in West North Central. This geographic variation in the type of naloxone dispensed partially reflects the different composition of prescriber types across divisions but is primarily driven by differences in the type of naloxone prescribed by primary care physicians; in the West North Central $81.5 \%$ of prescriptions by primary care providers were branded, $38.2 \%$ being Evzio $\AA$ compared with only $37.6 \%$ of prescriptions in New England, 2.2 being Evzio ${ }^{\circledR}$ (Table 2).

Differences by gender across provider specialty groups were modest, with the percent of female patients filling naloxone prescriptions ranging from $46 \%$ among emergency medicine prescribers, psychiatrists and addiction specialists, and surgeons to $57 \%$ among pain and anesthesia physicians (Fig. 2a). We observed more marked differences across prescriber groups in patients' age distribution. As Figure $2 b$ illustrates, patients filling prescriptions from pain and anesthesia physicians skewed older, with $75.2 \%$ being aged 46 years or older. Conversely, patients receiving naloxone from emergency medicine physicians or psychiatrists and addiction specialists were significantly younger than patients receiving naloxone from any other specialty group. Over $40 \%$ of dispensed naloxone prescriptions from emergency medicine physicians went to patients under age $36(6.3 \%$ under age $18,36.1 \%$ age 18 to 35 ), and $49.5 \%$ of naloxone prescriptions written by psychiatrists and addiction specialists were dispensed to patients ages 18 to 35 . As a result, although emergency medicine physicians accounted for $3.9 \%$ of all dispensed naloxone prescriptions, they were responsible for $26.2 \%$ of naloxone prescriptions filled by youth under age 18 and $6.0 \%$ of all prescriptions filled by individuals aged 18 to 35 . Similarly, psychiatrists and addiction specialists accounted for $6.1 \%$ of all dispensed naloxone prescriptions, but were responsible for $12.5 \%$ of all prescriptions filled by individuals aged 18 to 35 .

\section{DISCUSSION}

There has been exponential growth in the volume of naloxone being dispensed through retail pharmacies in the USA, in part driven by state implementation of naloxone access laws, such as those allowing access through standing orders or direct pharmacist dispensing. ${ }^{15-17}$ However, the number of naloxone prescriptions continues to be dwarfed by the number of people with active opioid use disorder, reporting opioid misuse, and receiving high-risk opioid analgesic prescriptions. ${ }^{7,18,19}$ These findings underscore the need for additional actions to equip atrisk individuals and those close to them with naloxone.

Primary care and internal medicine specialties, which account for the largest number of opioid prescriptions across multiple settings, ${ }^{20-22}$ are also responsible for the largest share of pharmacy-dispensed naloxone; yet, naloxone prescribing 
Table 2 Geographic Variation in Prescriber Specialties Writing Naloxone Prescriptions Dispensed Through Retail Pharmacies

\begin{tabular}{|c|c|c|c|c|c|c|c|c|c|}
\hline & \multicolumn{2}{|l|}{ Northeast } & \multicolumn{3}{|l|}{ South } & \multicolumn{2}{|l|}{ Midwest } & \multicolumn{2}{|l|}{ West } \\
\hline & $\begin{array}{l}\text { New } \\
\text { England }\end{array}$ & $\begin{array}{l}\text { Mid- } \\
\text { Atlantic }\end{array}$ & $\begin{array}{l}\text { South } \\
\text { Atlantic }\end{array}$ & $\begin{array}{l}\text { East South } \\
\text { Central }\end{array}$ & $\begin{array}{l}\text { West South } \\
\text { Central }\end{array}$ & $\begin{array}{l}\text { East North } \\
\text { Central }\end{array}$ & $\begin{array}{l}\text { West North } \\
\text { Central }\end{array}$ & Mountain & Pacific \\
\hline $\begin{array}{l}\text { Per capita rates of: } \\
\text { Naloxone }\end{array}$ & 98.5 & 20.7 & 45.6 & 38.3 & 20.8 & 20.6 & 10.4 & 42.3 & 21.4 \\
\hline $\begin{array}{l}\text { prescriptions } \\
\text { Naloxone } \\
\text { prescribers }\end{array}$ & 15.9 & 4.2 & 5.1 & 4.5 & 2.1 & 3.2 & 2.5 & 6.5 & 4.0 \\
\hline \multicolumn{10}{|c|}{ Per opioid overdose death (2015):* } \\
\hline $\begin{array}{l}\text { Naloxone } \\
\text { prescriptions }\end{array}$ & 4.5 & 1.9 & 4.0 & 3.0 & 3.6 & 1.4 & 1.4 & 3.7 & 3.4 \\
\hline \multicolumn{10}{|c|}{ Patients per prescriber: } \\
\hline Mean & 5.6 & 4.3 & 7.9 & 7.8 & 9.2 & 5.7 & 3.9 & 5.9 & 4.6 \\
\hline $\begin{array}{l}\text { Standard deviation } \\
{[\mathrm{IQR}]^{\dagger}}\end{array}$ & $\begin{array}{l}62.4 \\
{[1,2]}\end{array}$ & $\begin{array}{l}22.2 \\
{[1,2]}\end{array}$ & $\begin{array}{l}27.8 \\
{[1,4]}\end{array}$ & $\begin{array}{l}22.3 \\
{[1,4]}\end{array}$ & $\begin{array}{l}31.4 \\
{[1,5]}\end{array}$ & $\begin{array}{l}31.4 \\
{[1,2]}\end{array}$ & $\begin{array}{l}10.9 \\
{[1,2]}\end{array}$ & $\begin{array}{l}21.9 \\
{[1,3]}\end{array}$ & $\begin{array}{l}21.6 \\
{[1,3]}\end{array}$ \\
\hline $\begin{array}{l}\text { Upper adjacent } \\
\text { value }\end{array}$ & 3 & 3 & 8 & 8 & 11 & 3 & 3 & 6 & 6 \\
\hline $\begin{array}{l}\% \text { Rx by specialty: } \\
\text { Primary care } \\
\text { physicians }\end{array}$ & $59.9 \%$ & $53.8 \%$ & $22.4 \%$ & $30.2 \%$ & $13.4 \%$ & $38.8 \%$ & $48.4 \%$ & $34.5 \%$ & $33.2 \%$ \\
\hline pon-physicians & $24.6 \%$ & $19.3 \%$ & $41.1 \%$ & $43.3 \%$ & $19.3 \%$ & $21.1 \%$ & $22.7 \%$ & $40.4 \%$ & $28.7 \%$ \\
\hline $\begin{array}{l}\text { Pain \& anesthesia } \\
\text { physicians }\end{array}$ & $4.3 \%$ & $13.2 \%$ & $23.3 \%$ & $19.1 \%$ & $52.0 \%$ & $20.0 \%$ & $17.4 \%$ & $19.2 \%$ & $34.6 \%$ \\
\hline $\begin{array}{l}\text { Psychiatry \& } \\
\text { addiction specialists }\end{array}$ & $7.5 \%$ & $7.8 \%$ & $7.3 \%$ & $3.3 \%$ & $11.8 \%$ & $5.5 \%$ & $4.4 \%$ & $2.3 \%$ & $1.6 \%$ \\
\hline $\begin{array}{l}\text { Emergency } \\
\text { medicine }\end{array}$ & $2.5 \%$ & $4.6 \%$ & $4.4 \%$ & $2.8 \%$ & $1.4 \%$ & $13.5 \%$ & $3.5 \%$ & $1.5 \%$ & $0.8 \%$ \\
\hline Surgery & $1.0 \%$ & $1.1 \%$ & $1.3 \%$ & $0.9 \%$ & $2.0 \%$ & $0.9 \%$ & $3.3 \%$ & $1.6 \%$ & $1.0 \%$ \\
\hline Other & $0.3 \%$ & $0.1 \%$ & $0.2 \%$ & $0.4 \%$ & $0.1 \%$ & $0.1 \%$ & $0.3 \%$ & $0.5 \%$ & $0.1 \%$ \\
\hline $\begin{array}{l}\text { \% Rx by formulation: } \\
\text { Auto-injector } \\
\text { (Evzio) }\end{array}$ & $5.8 \%$ & $26.0 \%$ & $50.3 \%$ & $35.3 \%$ & $43.8 \%$ & $19.4 \%$ & $45.6 \%$ & $32.8 \%$ & $35.9 \%$ \\
\hline $\begin{array}{l}\text { Nasal spray } \\
\text { (Narcan) }\end{array}$ & $45.4 \%$ & $41.1 \%$ & $31.9 \%$ & $33.9 \%$ & $22.6 \%$ & $50.8 \%$ & $41.2 \%$ & $35.0 \%$ & $34.8 \%$ \\
\hline $\begin{array}{l}\text { Generic pre-filled } \\
\text { syringe }\end{array}$ & $44.7 \%$ & $23.4 \%$ & $11.1 \%$ & $13.3 \%$ & $26.8 \%$ & $23.2 \%$ & $4.1 \%$ & $26.2 \%$ & $16.1 \%$ \\
\hline Other generic & $4.1 \%$ & $9.5 \%$ & $6.7 \%$ & $17.4 \%$ & $6.8 \%$ & $6.6 \%$ & $9.1 \%$ & $6.1 \%$ & $13.1 \%$ \\
\hline
\end{tabular}

New England: $M E, N H, V T, M A, C T$, RI. Mid-Atlantic: NY, PA, NJ. South Atlantic: WV, MD, DE, DC, VA, NC, SC, GA, FL. East South Central: KY, TN, AL, MS. West South Central: TX, LA, OK, AR. East North Central: MI, WI, IL, IN, OH. West North Central: ND, SD, NE, KS, MO, MN, IA. Mountain: $I D, M T, W Y, C O, U T, N V, A Z, N M$. Pacific: AK, WA, OR, CA, HI. "Opioid overdose deaths for 2015 obtained from the Centers for Disease Control and Prevention Wide-ranging Online Data for Epidemiologic Research (CDC WONDER) system based on multiplecause of death codes that indicated drug overdose $(X 40-X 44, X 60-X 64, X 85$, and Y10-Y14) and opioid involvement (T40.0F40.4 and T40.6). IQR = Interquartile Range, representing the range between the first quartile (p25) and third quartile ( $p 75)$. * The upper adjacent value is the maximum value less than or equal to the upper inner fence, which is the third quartile ( $p 75$ ) plus $1.5 * I Q R$.

remains a relatively rare practice among these physicians. In 2016, we observed naloxone prescription fills written by 6437 unique primary care/internal medicine physicians, a small fraction of the more than 150,000 with at least 10 opioid claims filled for Medicare beneficiaries. ${ }^{20}$ Furthermore, these providers often prescribed naloxone to relatively few patients, with nearly $80 \%$ prescribing naloxone to only one or two patients. Given the magnitude of opioid prescribing nationwide, the large number of individuals using prescription or illicit opioids, and recent calls for greater naloxone/opioid coprescribing, our findings draw attention to the need for greater efforts to overcome primary care clinicians' limited clinical knowledge about and logistical barriers to prescribing naloxone. $^{23}$

Some individuals, such as those with chronic noncancer pain prescribed high-dose opioid regimens or those coprescribed benzodiazepines, ${ }^{24-26}$ appear to be at higher risk of opioid analgesic misuse and subsequent overdose. Among naloxone prescribing clinicians, we found pain medicine specialists, who prescribe significantly more opioid analgesics per capita than other specialties,(27) are responsible for a disproportionate share of pharmacy-dispensed naloxone. Our results suggest that almost one-third of an estimated 4600 active pain medicine and pain management physicians ${ }^{28}$ wrote a dispensed naloxone prescription in 2016, a substantially higher percentage than other specialty groups. However, the patients filling naloxone prescriptions written by pain management physicians skew female and older. Individuals younger than 35, particularly males, have experienced a dramatic increase in drug overdose death rates, driven in recent years by heroin and synthetic opioids rather than opioid analgesics. ${ }^{29}$ While this younger cohort now represents about $40 \%$ of all overdose deaths, ${ }^{30}$ they account for less than one-quarter of patients filling naloxone prescriptions. Furthermore, the providers prescribing naloxone to younger individuals are more commonly emergency medicine physicians and psychiatrists and addiction specialists, which may reflect greater awareness among these specialists of opioid overdose risk factors in this 


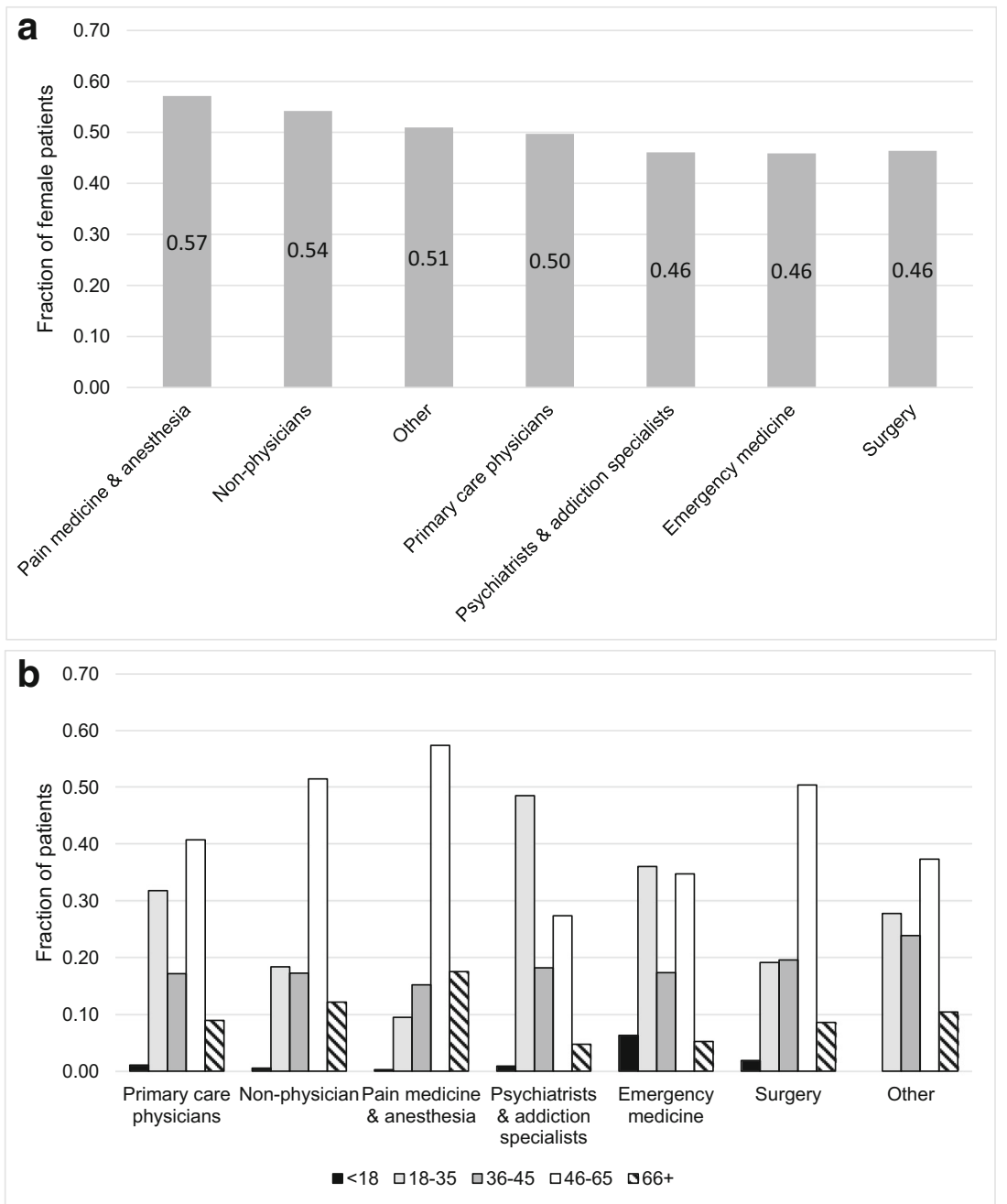

Figure 2 a Gender of patients filling naloxone Rx, by prescriber specialty group. b Age of patients filling naloxone $\mathbf{R x}$, by prescriber specialty group. For ease of interpretation, detailed age groups were collapsed as follows: $<18(<11,12-17), 18-3518-25,26-30,31-35,36-45(36-40,41-45)$, 46-65 (46-50, 51-55, 56-60, 61-65), 66+ (66-70, 71-75, 76-80, > 80)

population as well as differences in healthcare system utilization among younger cohorts. Given that the type of opioids used and that risk of opioid misuse and overdose may vary among populations being seen by different specialties, further research is needed to inform efforts to educate physicians and other prescribers regarding naloxone prescribing to their specific patient population and to increase the rates of prescribing among the many specialties with very low rates of prescribing.

We found substantial geographic variation in market share for different naloxone formulations; in New England, nearly half of pharmacy-dispensed naloxone is generic, whereas in the South Atlantic division over half is the Evzio ${ }^{\circledR}$ autoinjector. Consistent with other studies, ${ }^{8}$ we also found substantial geographic differences in per capita rates of naloxone prescription fills that did not always reflect geographic variation in the severity of the crisis. New England, with the highest rates of overdose mortality and opioid-related hospitalizations, ${ }^{31,32}$ correspondingly had both the highest rate of naloxone prescriptions and the highest rate per opioid overdose death, driven by substantially more naloxone prescribers in
New England relative to other census divisions - not by a greater volume of patients being prescribed naloxone by each provider. However, several other regions with similar naloxone dispensing rates have experienced dramatically different evolutions of the opioid crisis. For instance, while the 2016 naloxone prescription rates in the Pacific and East North Central divisions were nearly equivalent, the corresponding naloxone prescription rate per opioid-related overdose death differed by nearly threefold (3.4 vs. 1.4 , respectively). While some variation in prescribing rates and type of naloxone may reflect differences in state policies, such as naloxone access laws, by 2016, nearly every state had established standing order provisions or allowances for third-party prescribing. ${ }^{16}$ Thus, it is key to understand how state policies influencing pharmacy-dispensed naloxone may interact with other policies, particularly given how few naloxone-prescribing pharmacists we observe, which suggests that studies estimating the effects of pharmacist-focused laws may be picking up effects of the laws unrelated to changes in pharmacist behavior. Relatedly, we need to understand the impact of efforts to 
expand community-based overdose education and naloxone distribution programs as well as nurse practitioner and physician assistant scope of practice policies. Better understanding the latter may also enhance our understanding of the notable role of non-physicians in naloxone prescribing.

Using individual transaction-level pharmacy data allows us to examine provider and patient characteristics of naloxone distributed through retail pharmacies in a way not possible in studies using aggregate prescribing measures. However, the findings must be considered in the context of the study's limitations. Our dataset only includes information on naloxone prescriptions dispensed through retail pharmacies, failing to capture prescriptions written but not dispensed and naloxone distribution through non-pharmacy channels, such as through community-based naloxone distribution programs, emergency medical services personnel, or other first responder programs. We have limited information on patient characteristics, preventing us from examining other key demographic or clinical characteristics. It is possible that the person for whom the prescription has been written may not be the person for whom the naloxone is intended to be used (e.g., a parent filling a naloxone prescription due to concern about a child misusing opioids). The data only included information on naloxone prescriptions, making us unable to make provider-level comparisons to other prescribers who do not have an associated naloxone prescription dispensed within the data nor to assess to what extent naloxone is being co-prescribed with opioids. Furthermore, we only had data on naloxone prescriptions dispensed in 2016, and naloxone prescription fills have continued to increase due to heightened attention to expanding naloxone access, ${ }^{8}$ particularly in states that implemented coprescription laws requiring naloxone prescriptions for opioidreceiving patients at risk of an opioid overdose. ${ }^{33}$ Given efforts to increase naloxone prescribing, research examining future patterns and shifting trends will continue to be needed. Finally, we are unable to determine whether a prescription was dispensed via standing order or issued as a third-party prescription, nor does our cross-sectional data allow us to infer causal relationships.

Despite these limitations, our findings enhance our understanding of naloxone prescribing at a time of critically important efforts to expand naloxone availability in the prehospital setting. ${ }^{34,35}$ Such efforts are particularly needed at a time when higher potency synthetic opioids such as fentanyl and carfentanil, which can result in overdoses in smaller doses, are increasingly prevalent in many communities. ${ }^{13}$ Further aligning prescriber practice with guidelines that recommend naloxone co-prescribing to patients at risk for opioid overdose, ${ }^{11}$ along with reducing barriers to pharmacy-dispensed naloxone, naloxone distributed by overdose education and naloxone distribution programs, and naloxone administered by first responders, are critical components of our nation's response to the opioid crisis and are central to efforts to reduce fatal opioid-related overdoses.
Acknowledgments: The authors would like to thank Hilary Peterson for assistance in manuscript preparation.

Corresponding Author: Rosanna Smart, PhD; RAND Corporation, 1776 Main Street, Santa Monica, CA 90407-2138, USA (e-mail: rsmart@rand.org).

Funding Information This work was supported by the National Institute on Drug Abuse (NIDA) through R21 DA045950 (Smart, PI) and P5O DA046351 (Stein, PI).

\section{Compliance with Ethical Standards:}

The corresponding author's Institutional Review Board approved the study.

Conflict of Interest: The authors declare that they do not have a conflict of interest.

\section{REFERENCES}

1. Scholl L, Seth P, Kariisa M, Wilson N, Baldwin G. Drug and opioidinvolved overdose deaths-United States, 2013-2017. MMWR. 2019;67(5152): 1419 .

2. Gomes T, Tadrous M, Mamdani MM, Paterson JM, Juurlink DN. The burden of opioid-related mortality in the United States. JAMA Network Open. 2018;1(2):e180217-e.

3. Boyer EW. Management of opioid analgesic overdose. N Engl J Med. 2012;367(2):146-55

4. Sporer KA, Firestone J, Isaacs SM. Out-of-hospital treatment of opioid overdoses in an urban setting. Acad Emerg Med. 1996;3(7):660-7.

5. Gupta R, Shah ND, Ross JS. The rising price of naloxone—risks to efforts to stem overdose deaths. N Engl J Med. 2016;375(23):2213-5.

6. Jones CM, Lurie PG, Compton WM. Increase in naloxone prescriptions dispensed in US retail pharmacies since 2013. Am J Public Health. 2016;106:689-90

7. Guy GP, Haegerich TM, Evans ME, Losby JL, Young R, Jones CM. Vital Signs: Pharmacy-based naloxone dispensing-United States, 20122018. MMWR. 2019;68:679-86.

8. Freeman PR, Hankosky ER, Lofwall MR, Talbert JC. The changing landscape of naloxone availability in the United States, 2011-2017. Drug Alcohol Depend. 2018;191:361-4.

9. Davis C, Carr D. State legal innovations to encourage naloxone dispensing. J Am Pharm Assoc (2003). 2017;57(2S):S180-S4.

10. Davis CS, Carr D. Legal changes to increase access to naloxone for opioid overdose reversal in the United States. Drug Alcohol Depend. 2015;157:112-20.

11. Dowell D, Haegerich TM, Chou R. CDC Guideline for prescribing opioids for chronic pain-United States, 2016. J Am Med Assoc. 2016;315(15): 1624-45.

12. Statement from FDA Commissioner Scott Gottlieb, M.D. on unprecedented new efforts to support development of over-the-counter naloxone to help reduce opioid overdose deaths [press release]. Silver Spring, MD: U.S. Food and Drug Administration; 2019.

13. Centers for Disease Control and Prevention. Rising numbers of deaths involving fentanyl and fentanyl analogs, including carfentanil, and increased usage and mixing with non-opioids; 2018. Available at: https://emergency.cdc.gov/han/han00413.asp. Accessed August 15, 2019.

14. Seth P, Rudd RA, Noonan RK, Haegerich TM. Quantifying the epidemic of prescription opioid overdose deaths. American Public Health Association; 2018.

15. Abouk R, Pacula RL, Powell D. Association between state laws facilitating pharmacy distribution of naloxone and risk of fatal overdose. JAMA Intern Med. 2019;179(6):805-11.

16. Gertner AK, Domino ME, Davis CS. Do naloxone access laws increase outpatient naloxone prescriptions? evidence from Medicaid. Drug Alcohol Depend. 2018;190:37-41.

17. Xu J, Davis CS, Cruz M, Lurie P. State naloxone access laws are associated with an increase in the number of naloxone prescriptions dispensed in retail pharmacies. Drug Alcohol Depend. 2018;189:37-41. 
18. Center for Behavioral Health Statistics and Quality. 2017 National Survey on Drug Use and Health: Detailed Tables. Rockville: Substance Abuse and Mental Health Services Administration; 2018.

19. Schieber LZ, Guy GP, Seth P, Young R, Mattson CL, Mikosz CA, et al Trends and patterns of geographic variation in opioid prescribing practices by state, United States, 2006-2017. JAMA Network Open. 2019;2(3):e190665.

20. Hadland SE, Cerdá M, Li Y, Krieger MS, Marshall BD. Association of pharmaceutical industry marketing of opioid products to physicians with subsequent opioid prescribing. JAMA Intern Med. 2018;178(6):861-3.

21. Lev R, Lee O, Petro S, Lucas J, Castillo EM, Vilke GM, et al. Who is prescribing controlled medications to patients who die of prescription drug abuse? Am J Emerg Med. 2016;34(1):30-5.

22. Levy B, Paulozzi L, Mack KA, Jones CM. Trends in opioid analgesicprescribing rates by specialty, US, 2007-2012. Am J Prev Med. 2015;49(3):409-13.

23. Binswanger IA, Koester S, Mueller SR, Gardner EM, Goddard K, Glanz JM. Overdose education and naloxone for patients prescribed opioids in primary care: a qualitative study of primary care staff. J Gen Intern Med. 2015;30(12): 1837-44.

24. Campbell CI, Bahorik AL, VanVeldhuisen P, Weisner C, Rubinstein AL, Ray GT. Use of a prescription opioid registry to examine opioid misuse and overdose in an integrated health system. Prev Med. 2018;110:31-7.

25. Bohnert AS, Valenstein M, Bair MJ, Ganoczy D, McCarthy JF, Ilgen MA et al. Association between opioid prescribing patterns and opioid overdose-related deaths. JAMA. 2011;305(13):1315-21.

26. Dunn KM, Saunders KW, Rutter CM, Banta-Green CJ, Merrill JO, Sullivan MD, et al. Opioid prescriptions for chronic pain and overdose: a cohort study. Ann Intern Med. 2010;152(2):85-92.
27. Schnell M, Currie J. Addressing the opioid epidemic: is there a role for physician education? Am J Health Econ. 2018;4(3):383-410.

28. Association of American Medical Colleges. Active physicians by age and specialty, 2015; 2016. Available at: https://www.aamc.org/data/workforce/reports/458494/1-4-chart.html. Accessed August 15, 2019.

29. Hedegaard H, Miniño AM, Warner M. Drug overdose deaths in the United States, 1999-2017. Hyattsville: National Center for Health Statistics; 2018.

30. Multiple Cause of Death 1999-2017 on CDC WONDER Online Database, released December, 2018 [Internet]. National Center for Health Statistics; 2018. Available at: http://wonder.cdc.gov/mcd-icd10.html. Accessed January 29, 2019.

31. Centers for Disease Control and Prevention. Drug overdose deaths. 2018 Available at: https://www.cdc.gov/drugoverdose/data/statedeaths.html. Accessed August 15, 2019.

32. Unick GJ, Ciccarone D. US regional and demographic differences in prescription opioid and heroin-related overdose hospitalizations. Int $\mathrm{J}$ Drug Policy. 2017;46:112-9.

33. Sohn M, Talbert JC, Huang Z, Lofwall MR, Freeman PR. Association of naloxone coprescription laws with naloxone prescription dispensing in the United States. JAMA Network Open. 2019;2(6):e196215.

34. Morgan J, Jones AL. The role of naloxone in the opioid crisis. Toxicology Communications. 2018;2(1):15-8.

35. Adams JM. Increasing naloxone awareness and use: the role of health care practitioners. JAMA. 2018;319(20):2073-4.

Publisher's Note Springer Nature remains neutral with regard to jurisdictional claims in published maps and institutional affiliations. 